\title{
Effects of Probiotic Culture Supernatant on Cariogenic Biofilm Formation and RANKL-Induced Osteoclastogenesis in RAW 264.7 Macrophages
}

\author{
Jae-In Jung ${ }^{1}{ }^{\oplus}$, Seung-Min Baek ${ }^{1}$, Trung Hau Nguyen ${ }^{2}$, Jin Woo Kim ${ }^{2}$, Chang-Ho Kang ${ }^{2}{ }^{\circledR}$, Seonyoung Kim ${ }^{2}$ \\ and Jee-Young $\operatorname{Imm} 1, *$ D \\ 1 Department of Foods and Nutrition, Kookmin University, Seoul 02707, Korea; shinseo23@naver.com (J.-I.J.); \\ doriya50@naver.com (S.-M.B.) \\ 2 MEDIOGEN, Co., Ltd., Jecheon 27159, Korea; hau2807@naver.com (T.H.N.); valdicava@naver.com (J.W.K.); \\ changho-kang@naver.com (C.-H.K.); clsrn3423@naver.com (S.K.) \\ * Correspondence: jyimm@kookmin.ac.kr; Tel.: +82-10-2526-1219
}

check for

updates

Citation: Jung, J.-I.; Baek, S.-M.; Nguyen, T.H.; Kim, J.W.; Kang, C.-H.; Kim, S.; Imm, J.-Y. Effects of Probiotic Culture Supernatant on Cariogenic Biofilm Formation and RANKLInduced Osteoclastogenesis in RAW 264.7 Macrophages. Molecules 2021, 26, 733. https://doi.org/10.3390/ molecules 26030733

Academic Editors: Vincenzo De Feo and Alexandru Mihai Grumezescu

Received: 17 December 2020

Accepted: 28 January 2021

Published: 31 January 2021

Publisher's Note: MDPI stays neutral with regard to jurisdictional claims in published maps and institutional affiliations.

Copyright: (C) 2021 by the authors Licensee MDPI, Basel, Switzerland. This article is an open access article distributed under the terms and conditions of the Creative Commons Attribution (CC BY) license (https:/ / creativecommons.org/licenses/by/ $4.0 /)$.

\begin{abstract}
Postbiotics are a promising functional ingredient that can overcome the limitations of viability and storage stability that challenge the production of probiotics. To evaluate the effects of postbiotics on oral health, eight spent culture supernatants (SCSs) of probiotics were prepared, and the effects of SCSs on Streptococcus mutans-induced cariogenic biofilm formation and the receptor activator of the nuclear factor $\mathrm{\kappa B}$ ligand (RANKL)-induced osteoclastogenesis were evaluated in RAW 264.7 macrophages. SCS of Lactobacillus salivarius MG4265 reduced S. mutans-induced biofilm formation by $73 \%$ and significantly inhibited tartrate-resistant acid phosphatase (TRAP) activity, which is a biomarker of mature osteoclasts in RAW 264.7 macrophages. The suppression of RANKLinduced activation of mitogen activated the protein kinases (c-Jun N-terminal kinase, extracellular signal-regulated kinase, and p38) and nuclear factor $\mathrm{kB}$ pathways, as well as the upregulation of heme oxygenase-1 expression. The suppression of RANK-L-induced activation of mitogen also inhibited the expression of transcriptional factors (c-fos and nuclear factor of activated T cells cytoplasmic 1) and, subsequently, osteoclastogenesis-related gene expression (tartrate-resistant acid phosphatasepositive (TRAP), cathepsin K, and matrix metalloproteinase-9).Therefore, SCS of L. salivarius MG4265 has great potential as a multifunctional oral health ingredient that inhibits biofilm formation and suppresses the alveolar bone loss that is associated with periodontitis.
\end{abstract}

Keywords: spent culture supernatant; Streptococcus mutans; biofilm formation; osteoclastogenesis

\section{Introduction}

Probiotics are defined as viable microorganisms that exert health benefits on the host when they are consumed in sufficient amounts [1]. The beneficial health effects of probiotics are strain-specific and related to several fundamental mechanisms, such as competition with pathogens [2], reinforcement of the intestinal barrier function [3], modulation of immune responses [4], and production of neurotransmitters [5]. Postbiotics refer to diverse metabolites or microbial components produced by probiotics during fermentation. Postbiotics are an emerging functional ingredient since they effectively increase the efficacy of probiotics without causing problems related to colonization and viability [6,7]. Cell-free probiotic culture supernatants are characterized as a typical type of postbiotics. Considering that postbiotics are mixture of various compounds produced during fermentation, they display broad bioactivity spectrum and have synergistic activity between various compounds [8]. There has been an increase in the application of postbiotics in food processing, and the fabrication of postbiotic-incorporated edible antimicrobial film has been the subject of considerable interest $[9,10]$.

Oral diseases, such as dental caries and periodontal diseases (gingivitis and periodontitis), are among the most prevalent global diseases and have physical, psychological, and 
economic consequences. Furthermore, normal oral function significantly affects the quality of life [11]. The oral cavity harbors more than 1000 microbial species and establishes a dynamic balance between microbial species [12]. Application of probiotics can contribute to the homeostasis of oral microflora by inhibiting the growth of periodontal pathogens and the modulation of the host immune responses [13].

Streptococcus mutans is a gram-positive facultative anaerobic bacterium that causes dental caries in the oral cavity. S. mutans produces dental plaque and creates acidic environment in the oral cavity [14]. Several studies have demonstrated that culturing S. mutans in the probiotic supernatants or coculturing S. mutans with probiotics reduced S. mutansmediated biofilm formation [15-17]. Bacterial accumulation in the oral cavity also triggers inflammation in gingival tissue and increases inflammatory cytokines and oxidative stress, leading to periodontal diseases causing gum damage and alveolar bone loss $[18,19]$. Nuclear factor $\mathrm{kB}$ ligand (RANKL)-mediated osteoclast differentiation is also closely related to alveolar bone loss in periodontal disease [20]. Thus, suppression of osteoclast differentiation can ameliorate osteoclast-related disorders including periodontitis. Liu et al. [21] reported that the ethanol extract of Lactobacillus paracasei subsp. paracasei NTU 101-fermented skim milk significantly suppressed periodontal inflammation in lipopolysaccharide (LPS)induced periodontitis rat model. Application $(0.1 \mathrm{~mL}, 2$ times/day for 14 days) of a Weissella cibaria suspension $\left(5 \times 10^{9} \mathrm{CFU} / \mathrm{mL}\right)$ on the gingival sulcus reduced alveolar bone loss in ligature-induced experimental periodontitis mice model [22].

The present study was conducted to identify potential biotherapeutic culture supernatants for the development of functional oral health ingredients. To achieve this goal, the effect of culture supernatants on the growth of $S$. mutans and biofilm formation were examined. Furthermore, we systemically investigated the effects of a selected culture supernatant (Lactobacillus salivarius MG4265) on RANKL-induced osteoclastogenesis and related molecular mechanisms.

\section{Results and Discussion}

\subsection{Effect of Probiotic Strains on the Growth of S. mutans}

The potential inhibitory activity of eight probiotic strains on the growth of $S$. mutans was evaluated (Figure 1A). The tested probiotic strains significantly suppressed the growth of S. mutans. The highest inhibitory activity was obtained with Lactococcus lactis MG5125 and L. salivarius MG4265. When the spent culture supernatants (SCSs) of the probiotic strains were used, there was an overall significant reduction in the growth of $S$. mutans. SCS of Lactobacillus fermentum MG901 showed lower inhibitory effect on S. mutans compared to other SCSs, while no clear differences were observed among other SCSs (Figure 1B). Similarly, SCSs obtained from several Lactobacillus spp. with different metabolic patterns (Lactobacillus salivarius, Lactobacillus casei, Lactobacillus plantarum, and Lactobacillus reuteri) resulted in a significant reduction in the growth $S$. mutans as determined at $600 \mathrm{~nm}$ but no difference was detected among the samples [16]. These results suggest that the tested probiotic strains produced metabolites or extracellular components that have an ability to inhibit growth of $S$. mutans.

S. mutans is an acid-producing bacterium and can tolerate acidic environments. The glucosyltransferase-expressing ability to synthesize water-insoluble glucans contributes to its virulence traits [14]. Lactobacillus spp.-mediated growth inhibition of S. mutans was demonstrated in humans, and considerable differences were found in oral lactobacilli between individuals containing no dental caries and active caries [23].

Tong et al. [24] reported that Lactococcus latis exerted an antagonizing effect against growth of S. mutans, especially under nutrient-deficient conditions, and delayed the incidence of dental caries. Two L. lactis strains, HY 449 and ATCC 19435, significantly downregulated expression of the glucosyltransferase gene ( $g t f s)$ of S. mutans [25]. Two L. salivarius strains, K35 and K43, which have strong inhibitory activity on the growth and biofilm formation of $S$. mutans, have been identified [26]. The anticariogenic activity 
of these two strains is greater than that of Lactobacillus rhamnosus GG (LGG), and they effectively downregulate glucosyltransferase-encoding genes $(g t f B, g t f C$, and $g t f D)$.

(A)

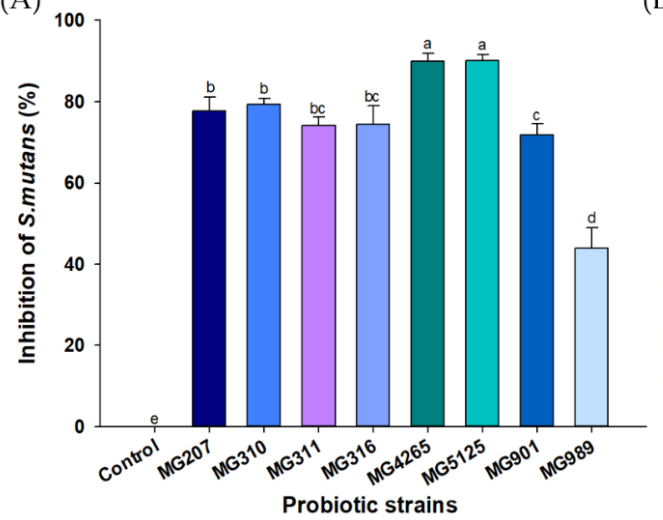

(B)

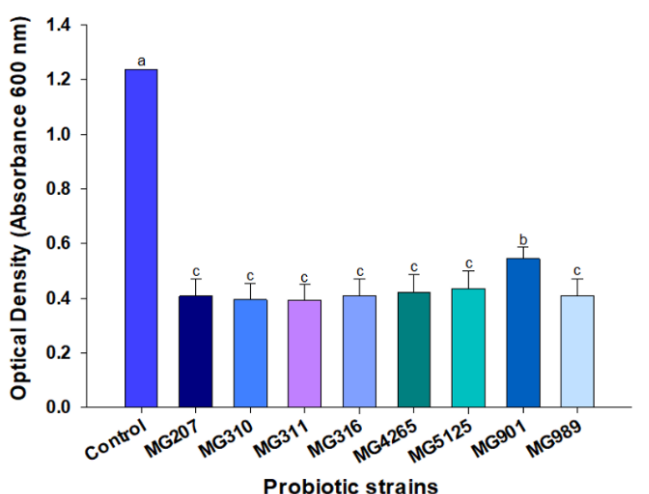

Figure 1. Effect of (A) probiotic strains and (B) their spent culture supernatants (SCSs) on the growth of S. mutans. Different letters (a-e) indicate significant difference at $p<0.05$.

\subsection{Effect of SCSs on S. mutans-Induced Preformed Biofilm Formation}

Numerous studies have reported that lactobacilli produce various secondary metabolites that have been characterized as antibacterial substances, such as organic acids (primarily acetic acid and lactic acid), peptides (biosurfactant and bacteriocins), and hydrogen peroxide $[17,27,28]$. The use of probiotic supernatants without live cells might be more advantageous in preventing dental caries because, although live bacteria such as Lactobacillus fermentum NCINB 5221-inhibited S. mutans have attached to gingival epithelial cells as a co-aggregated complex with S. mutans [29]. Additionally, based on an investigation of the correlation between oral lactobacilli and dental caries, few lactobacilli were found in the oral cavities of caries-free children [30]. Thus, we examined the effect of SCSs from probiotic strains on S. mutans-induced preformed biofilm formation (Figure 2). L. lactis MG5125, L. salivarius MG4265, Lactobacillus casei MG311, and Lactobacillus rhamnosus MG316 supernatants showed a stronger reducing activity on the $S$. mutans-induced biofilm than other SCSs $(p<0.05)$.

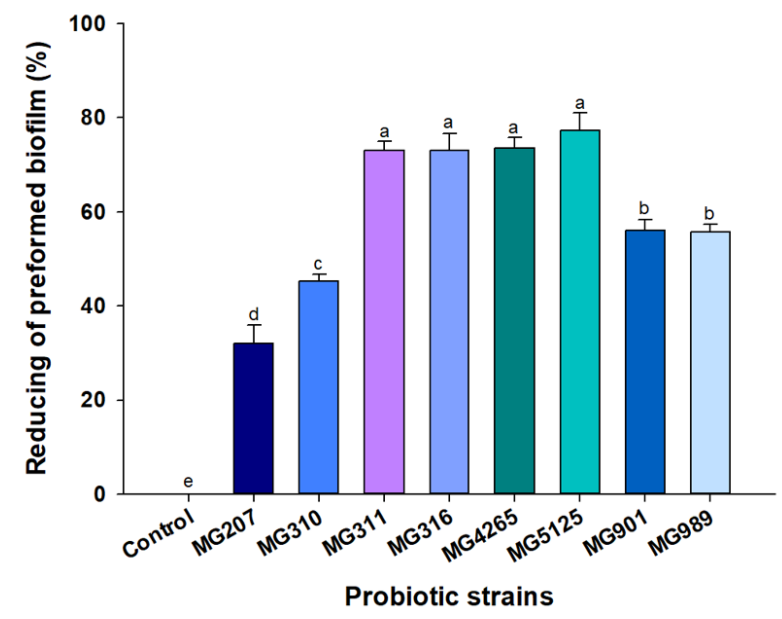

Figure 2. Reducing activity of SCSs of probiotic strains on S. mutans-induced biofilm. Different letters (a-e) indicate significant difference at $p<0.05$.

This result suggests that Lactobacillus strains release bioactive substances that suppress S. mutans-induced biofilm formation, and this anti-biofilm formation effect is strain-specific. Dental plaque is a biofilm structure and consists of caries-related bacterial cells and an extracellular matrix [31]. Considering that the cariogenic activity of $S$. mutans is mainly due 
to its ability to adhere to teeth and produce exopolysaccharide [32], the biofilm-reducing activity of parabiotics is essential for the prevention of dental caries. Wasfi et al. [16] reported that the SCS of L. salivarius exerted the greatest reduction activity on the $S$. mutansinduced biofilm. The L. salivarius-mediated antibiofilm effect was attributed to significant downregulation of the $g t f B$ gene of $S$. mutans. In this context, transcriptional gtfs gene regulation by the probiotic Lactobacillus strains positively contributed to the homeostasis of the oral microbiome [33].

Surface-active protein-rich biosurfactants derived from lactobacilli possibly decrease surface tension and inhibit biofilm formation [34,35].

L. plantarum lipoteichoic acid (a cell-wall component of gram-positive bacteria) suppressed S. mutans-induced biofilm formation by interfering with sucrose degradation, which is required for exopolysaccharide synthesis. The structural differences in the Dalanine repeating unit and glycolipid in lipoteichoic acid are responsible for selective inhibitory activity [36].

Based on the above results, the SCSs of L. lactis MG5125 and L. salivarius MG4265 have the potential to ameliorate dental caries by inhibiting the growth of S. mutans (Figure 1) and its biofilm formation (Figure 2).

\subsection{Effect of SCSs on RANKL-Induced Osteoclast Differentiation}

Osteoclasts are multinuclear cells that originate from precursor cells, such as monocyte or macrophage lineages, and play key roles in the bone loss from osteoporosis and periodontitis [37]. RAW 264.7 macrophages have been widely used as in vitro models of osteoclastogenesis since they are easily differentiated to osteoclasts by RANKL stimulation [38]. Tartrate-resistant acid phosphatase-positive (TRAP) activity was used to determine whether two preselected SCSs (L. salivarius MG4265 and L. lactis MG5125) also had a beneficial effect on RANKL-induced osteoclast formation in RAW 264.7 cells. L. salivarius MG4265 significantly reduced TRAP activity in RANKL-stimulated differentiated RAW 264.7 cells $(p<0.05$, Figure 3A), whereas there was no significant difference in the case of L. lactis MG5125. The SCS of L. salivarius MG4265 significantly inhibited TRAP activity in a dose-dependent manner $(p<0.05$, Figure 3B) and did not exhibit any cytotoxicity at the tested concentrations ( $p<0.05$, Figure 3C) These results indicate that the SCS of L. salivarius MG4265 actively suppressed RANKL-induced osteoclastogenesis. Thus, we further analyzed the effect of the SCS of L. salivarius MG4265 on osteoclast specific transcriptional factors and osteoclast associated genes expression.

\subsection{Effect of the SCS of L. salivarius MG4265 on Osteoclast Specific Transcriptional Factors and} Osteoclast-Associated Gene Expression

RANKL is an essential signaling molecule, and binding of RANKL to its receptor RANK induces the differentiation and activation of osteoclasts. This interaction stimulates the expression of osteoclast-specific key transcriptional effectors such as c-Fos and NFATc1 [39]. The effect of the SCS of L. salivarius MG4265 on the gene expression of these two transcriptional factors was examined using qRT-PCR. The gene expression of $c$-Fos and nuclear factor of activated T cells cytoplasmic 1 (NFATc1) was decreased by $55 \%$ and $27 \%$, respectively, in response to $50 \mu \mathrm{g} / \mathrm{mL}$ MG4265 treatment (Figure 4A,B).

NFATC1 is a master regulator of osteoclast activation and modulates osteoclast adhesion and absorption of bone matrices through the upregulation of TRAP, cathepsin K, and matrix metalloproteinase-9 (MMP-9) [40,41]. The induction of NFATc1 is governed by c-Fos and $c$-Fos overexpression and has been recovered decreased NFATc1 expression by a p38-specific inhibitor $[42,43]$.

Osteoclast-specific gene expression, including TRAP, cathepsin $\mathrm{K}$, and MMP-9 was also significantly decreased by treatment of MG4265 in a dose-dependent manner (Figure 5). Cathepsin $\mathrm{K}$ expression reflects the number of osteoclasts since it is mainly expressed in mature osteoclasts [44]. TRAP, cathepsin K, and MMP-9 play a key role in osteoclastmediated degradation of bone organic matrices such as collagen and osteopontin $[45,46]$. Downregulation of TRAP, cathepsin K, and MMP-9 by L. salivarius MG4265 indicates that 
MG4265 can effectively inhibit bone resorption via regulation of osteoclast proteases. It has been demonstrated that the suppression of RANKL-mediated osteoclastogenesis in the RAW 264.7 cell model was highly correlated with decreased bone loss in ovariectomized rats [47].

(A)

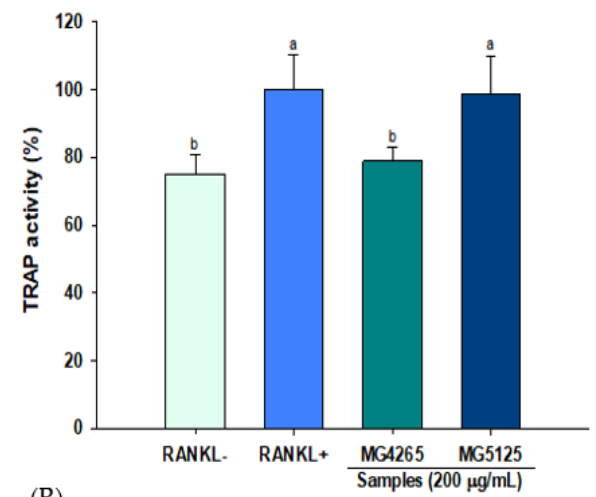

(B)

(C)
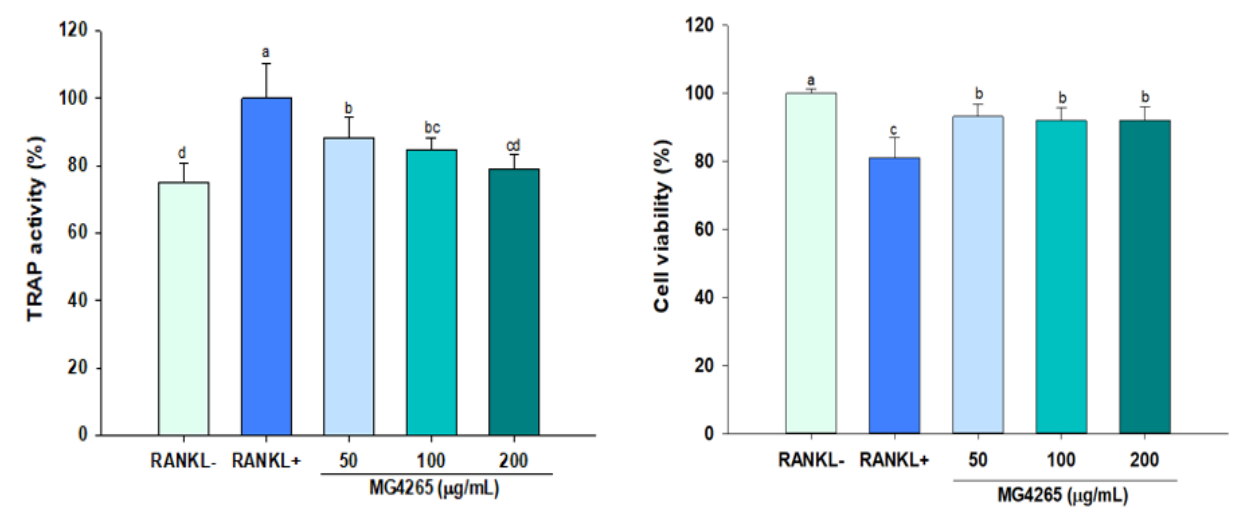

Figure 3. Effect of SCS produced from L. salivarius MG4265 and L. lactis MG5125 on (A) Tartrateresistant acid phosphatase-positive (TRAP) activity, (B) concentration dependent effect, and (C) cell viability in nuclear factor $\mathrm{KB}$ ligand (RANKL) stimulated RAW 264.7 macrophages. Different letters (a-d) indicate significant difference at $p<0.05$.

(A)

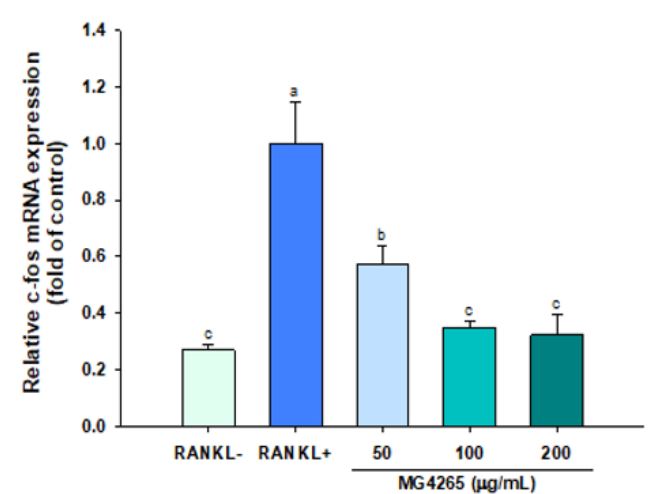

(B)

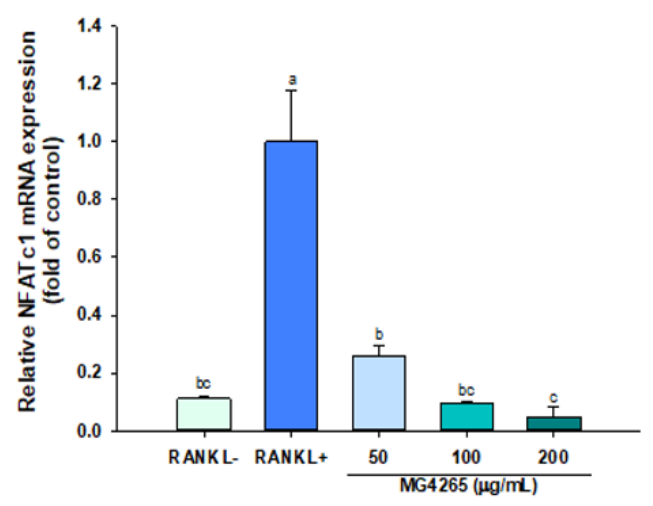

Figure 4. Effect of the SCS of L. salivarius MG4265 on osteoclast-specific transcription factors (A) c-Fos and (B) NFATc1 mRNA expression in RANKL stimulated RAW 264.7 macrophages. Different letters (a-c) indicate significant difference at $p<0.05$. 
(A)

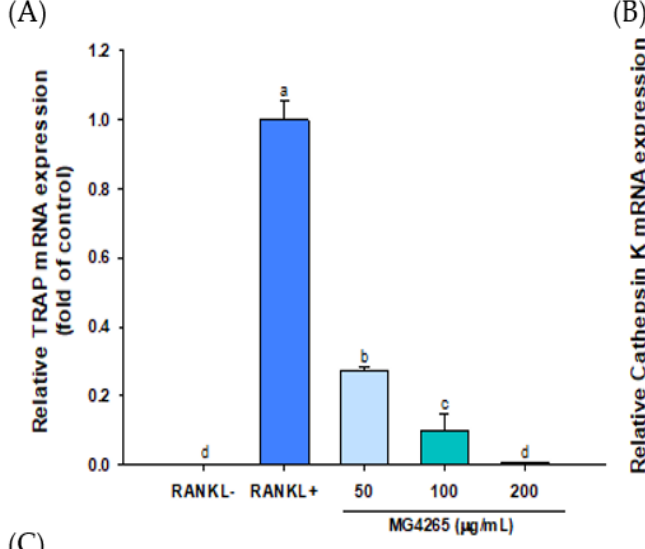

(C)

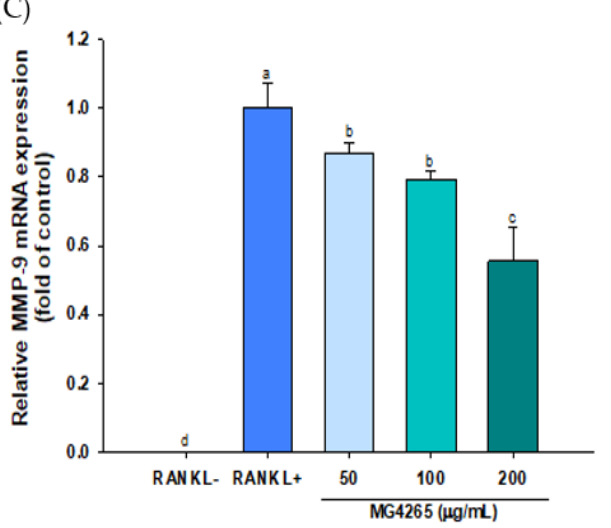

(B)

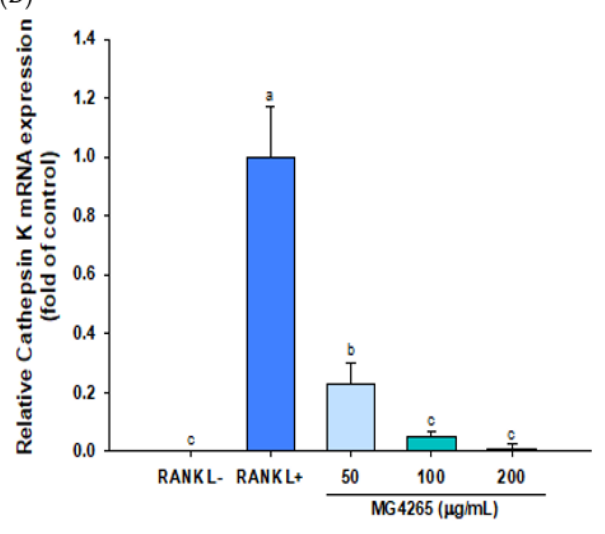

Figure 5. Effect of the SCS of L. salivarius MG4265 on osteoclast-specific (A) TRAP, (B) cathepsin K, and (C) MMP-9 mRNA expression in RANKL-stimulated RAW 264.7 macrophages. Different letters (a-d) indicate significant difference at $p<0.05$.

\subsection{Effect of the SCS of L. salivarius MG4265 on RANKL-Induced Mitogen Activated Protein Kinase (MAPKs) Activation}

RANKL/RANK binding on osteoclast precursors such as RAW 264.7 cells recruits TNF receptor associated factor 6 (TRAF6), which mediates downstream signaling cascades. It is well known that MAPKs, such as c-Jun N-terminal kinase (JNKs), extracellular signalregulated kinase (ERKs), and p38, are involved in osteoclast metabolism [48].

NF- $\mathrm{KB}$ is another crucial target of RANKL signaling, and selective inhibition of NF- $\mathrm{kB}$ nuclear translocation has been suggested as a therapeutic target for inflammatory bone loss [49]. Thus, the effect of the SCS of L. salivarius MG4265 on RANKL-mediated MAPK activation and NF- $\mathrm{KB}$ signaling were analyzed by Western blotting to investigate the molecular mechanisms related to c-Fos and NFATc1 downregulation.

The phosphorylation of all MAPKs was significantly increased upon RANKL stimulation. Also, L. salivarius MG4265 treatment markedly inhibited the phosphorylation of all three MAPKs and the nuclear translocation of NF-KB (Figure 6). These results indicate that the SCS of $L$. salivarius MG4265 inhibited osteoclastogenesis by blocking the RANKLactivated MAPK and NF- $\mathrm{KB}$ signaling cascades, consequently downregulating $c-$ Fos and NFATc1 gene expression in osteoclast precursors.

The combination of RANKL and interleukin- $1 \beta$, an inflammatory cytokine, synergistically activated ERK during osteoclastogenesis [50]. RANKL is a potent activator of JNK pathway, and the blocking of JNK signaling with a specific JNK inhibitor (SP600125) effectively reduced MMP expression and bone absorption in inflammatory arthritis rats [51]. Stimulation of p38 triggers the activation of osteoclastogenesis-specific transcriptional factors, such as NFATc1, and upregulates target gene expressions, such as cathepsin K [52].

$\mathrm{NF}-\mathrm{kB}$ is normally confined to the cytoplasm in a complex with inhibitory $\kappa B(\mathrm{I} \kappa \mathrm{B})$, and it enters the nucleus upon degradation of I $\kappa B$ by RANKL or inflammatory cytokines. 
Liberated NF- $\mathrm{kB}$ binds to DNA target sites and expresses MMP-9, which leads to inflammatory bone damage $[49,53]$.

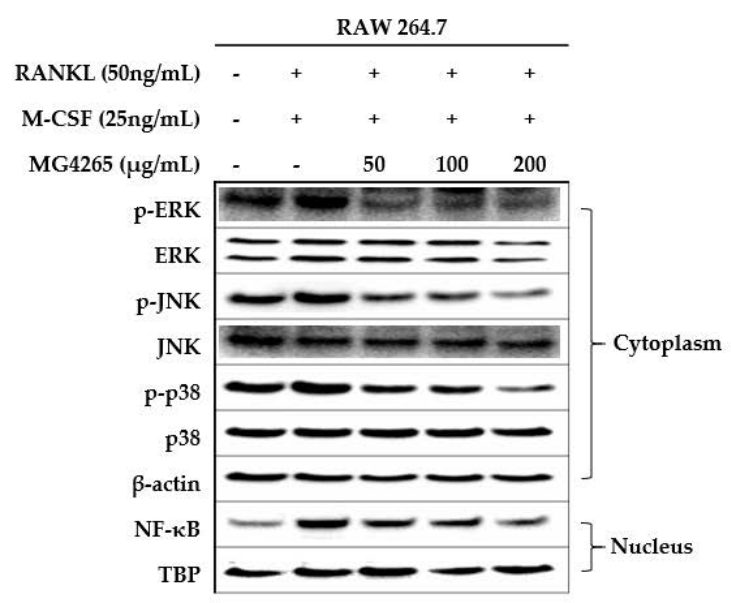

(A)

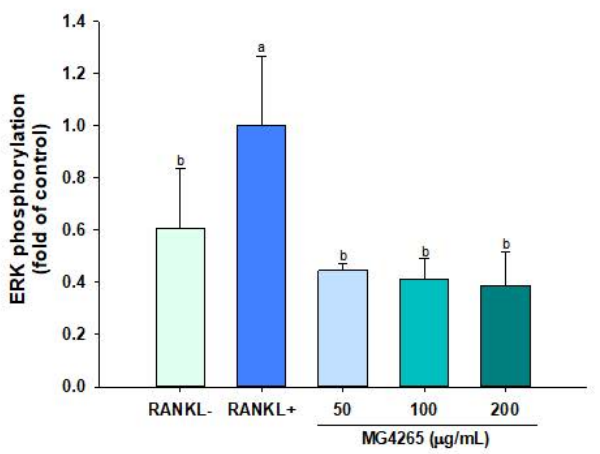

(C)

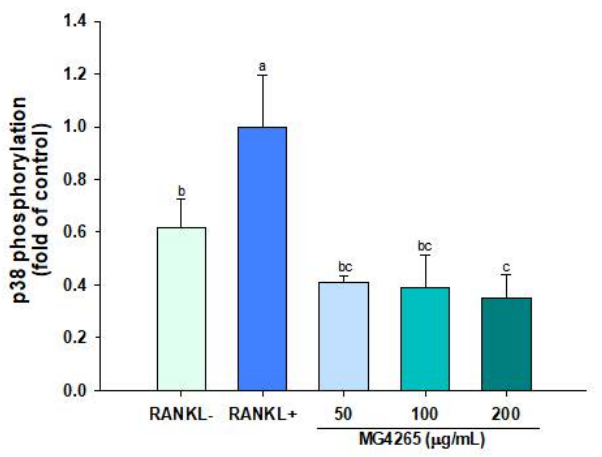

(B)

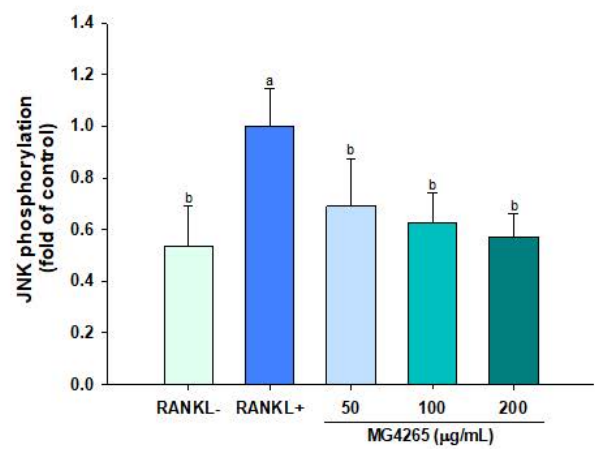

(D)

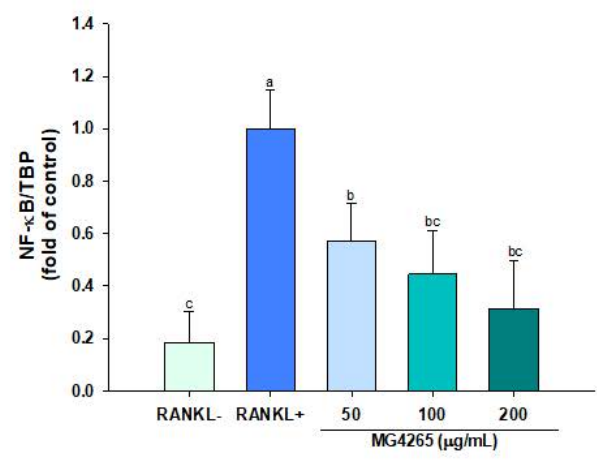

Figure 6. Effects of the SCS of L. salivarius MG4265 on (A) extracellular signal-regulated kinase (ERK), (B) c-Jun N-terminal kinase (JNK), (C) p38, and (D) nuclear NF- $\mathrm{BB}$ expression in RANKL-induced RAW 264.7 macrophages. Different letters $(\mathrm{a}-\mathrm{c})$ indicate significant difference at $p<0.05$.

There are only a few reports regarding parabiotics that attenuate periodontitis. In one study, the culture medium of Lactobacillus reuteri 6475 significantly suppressed RANKLinduced osteoclastogenesis in RAW 264.7 cells, and the authors suggested that lactobacillic acid was one of the active metabolites. GPR 120, a long-chain fatty acid receptor, was activated by the L. reuteri 6475 culture supernatant, and the MAPK pathway was involved in the suppression of osteoclastogenesis $[54,55]$. 


\subsection{Effect of the SCS of L. salivarius MG4265 on HO-1 Induction}

HO-1 is a stress-induced enzyme that modulates oxidative and inflammatory stress, and various phytochemicals inducing HO-1 have successfully inhibited RANKL-induced osteoclast differentiation [22,56]. RANKL exposure resulted in increased HO-1 expression, and it was further increased even with $50 \mu \mathrm{g} / \mathrm{mL}$ MG4265 treatment (Figure 7). The HO-1 induction was increased by 3.3-fold with treatment of $200 \mu \mathrm{g} / \mathrm{mL}$ of L. salivarius MG4265 $(p<0.05)$.
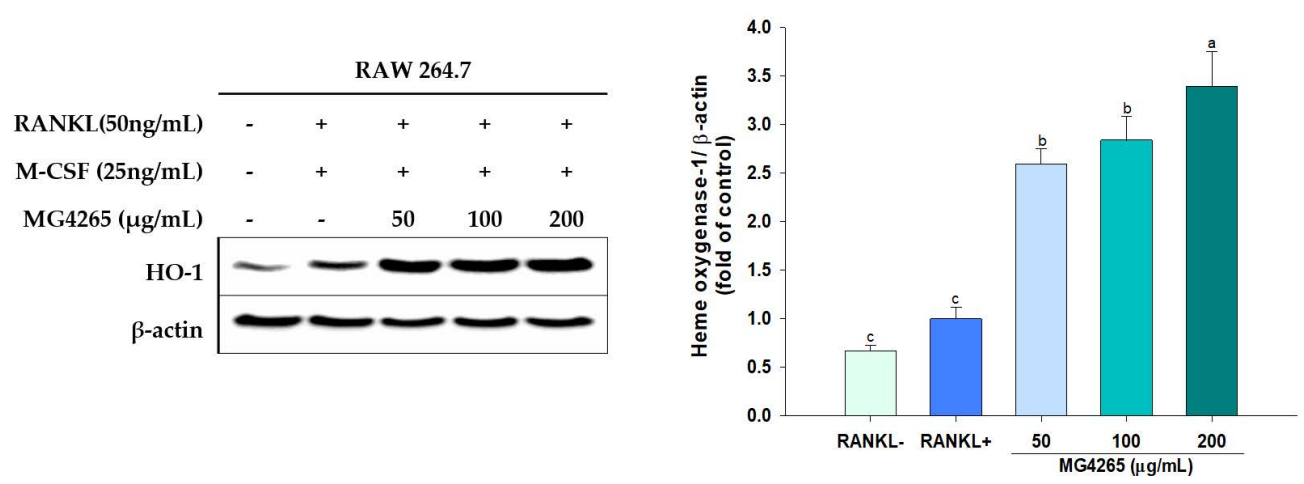

Figure 7. Effect of the SCS of L. salivarius MG4265 on HO-1 induction in RANKL-stimulated RAW 264.7 macrophages. Different letters $(\mathrm{a}-\mathrm{c})$ indicate significant difference at $p<0.05$.

In a pathophysiological state, free heme content derived from myoglobin or other hemoproteins increases and iron atoms of hemes exert oxidative stress by catalyzing excess reactive oxygen species (ROS) production [57]. Periodontal disease is also under the influence of ROS produced from both the host and bacteria. Although the direct mechanisms are not clear, ROS is indirectly involved in periodontal tissue destruction by the stimulation of bone matrix proteinases [58]. In this regard, the SCS of L. salivarius MG4265 can alleviate periodontal disease by inhibiting $S$. mutans growth and its exopolysaccharide production. Mutan isolated from S. mutans directly induced differentiation of osteoclasts and accelerated alveolar bone loss in rats [59]. In addition, SCS of L. salivarius MG4265 have a positive effect on periodontal diseases through the modulation of osteoclastogenesis. L. salivarius MG4265 can decrease periodontal tissue damage by inhibiting the gene expression of encoding bone matrix degradation enzymes such as TRAP, cathepsin K, and MMP-9.

The efficacy of freeze-dried probiotic tablets containing Lactobacillus salivarius WB21 was demonstrated in randomized, double-blind, and placebo-controlled 8-week intervention study. Clinical parameters such as plaque index and probing pocket depth were significantly improved in the test group compared with those in the placebo group [60].

Lipoteichoic acid is a major virulence factor in S. mutans. It is involved in bacterial adhesion to dentin and eventually elicits host immune responses [61]. Considering that SCS of L. salivarius MG4265 actively decreased S. mutans-induced biofilm formation and RANKL-induced osteoclastogenesis, metabolites that were produced during fermentation possibly acted as effector molecules. The genus Lactobacillus secretes various metabolites, such as muropeptides, aggregation-promoting factors, bacteriocin, short-chain fatty acids, and trytophan-related metabolites [62,63], which may suppress biofilm formation and immune regulation.

SCFA acts as a key regulator of bone formation and absorption. Butyric acid and L. rhamnosus GG (LGG) exhibited equal activity in improving bone density [64]. The ethanol extract from L. paracasei subsp. paracasei NTU-fermented skim milk improved LPS-induced periodontal inflammation and decreased alveolar bone loss [21]. A mixture of tyrosine and lactic acid in a ratio of 3:1 was identified as an anti-periodontitis ingredient in the fermented extract [65].

Krzy'sciak et al. [66] reported that Lactobacillus salivarius HM6 Paradens significantly reduced the double-species biofilm of $S$. mutans and Candida albicans isolated from the dental caries of children. They further explained that $L$. salivarius might release agents that 
are able to inhibit cariogenic biofilm, but they could not identify active compounds that block biofilm formation or its mode of action. Characterization of the active compounds in SCS of L. salivarius MG4265 is required in future studies.

\section{Materials and Methods}

\subsection{Strains and Cultivation}

Eight probiotic strains (Lactobacillus plantarum MG207 (isolated from kimchi), Lactobacillus paracasei MG310 (isolated from fermented food), L. casei MG311 (isolated from fermented food), L. rhamnosus MG316 (isolated from infant feces), L. salivarius MG4265 (isolated from human origin), L. lactis MG5125 (isolated from fermented food), L. fermentum MG901 (human origin), and Lactobacillus plantarum MG989 (human origin)) were kindly provided from MEDIOGEN (Jecheon, Republic of Korea). S. mutans KCTC3065 was purchased from the Korean Collection for Type Culture (Daejeon, Republic of Korea). Probiotic strains were cultured in de Man, Rogosa, and Sharpe (MRS) broth (1\% peptone, $0.8 \%$ meat extract, $0.4 \%$ yeast extract, $2 \%$ glucose, $0.5 \%$ sodium acetate, $0.2 \%$ dipotassium hydrogen phosphate, $0.02 \%$ magnesium sulfate heptahydrate, $0.005 \%$ manganese sulfate tetrahydrate, $0.02 \%$ triammonium citrate). S. mutans was cultured in brain-heart infusion (BHI) media $(0.77 \%$ calf brains, $0.98 \%$ beef heart, $1 \%$ proteose peptone, $0.2 \%$ dextrose, $0.5 \%$ sodium chloride, $0.25 \%$ disodium phosphate). Probiotic strains were cultured at $37^{\circ} \mathrm{C}$ in a $\mathrm{CO}_{2}$ incubator (Vision Scientific, Daejeon, Korea), and S. mutans was anaerobically cultured using GasPakTM EZ container systems (Becton Dickinson \& Co., Sparks, MD, USA) at $37^{\circ} \mathrm{C}$.

\subsection{Preparation of SCSs}

The SCSs of probiotic strains were prepared according to the method of Lin et al. [17]. Probiotic strains were grown in MRS at $37^{\circ} \mathrm{C}$ for $48 \mathrm{~h}$. SCSs were obtained by centrifugation at $3470 \times g$ for $10 \mathrm{~min}$ followed by filtration using $0.2 \mu \mathrm{m}$ filters (Advantec, Tokyo, Japan). The supernatants were lyophilized and used in the biofilm inhibition assay and cell culture study.

\subsection{Effect of Probiotic Strains on the Growth of S. mutans}

The effect of probiotic strains on the growth of $S$. mutans was examined using the method of Lin et al. with slight modifications [17]. The probiotic strains were grown in MRS at $37^{\circ} \mathrm{C}$ for $48 \mathrm{~h}$, and S. mutans was cultured in a BHI medium at $37^{\circ} \mathrm{C}$ for $48 \mathrm{~h}$ under anaerobic stationary conditions. The concentrations of each probiotic strain and S. mutans were adjusted to $108 \mathrm{CFU} / \mathrm{mL}$ using phosphate-buffered saline (PBS). Finally, $50 \mu \mathrm{L}$ of the S. mutans and each probiotic culture were combined and incubated under microaerophilic conditions at $37^{\circ} \mathrm{C}$ for $24 \mathrm{~h}$. After incubation, the suspensions were plated on MSB (Mitis Salivarius Sucrose Bacitracin) agar (Kisanbio, Seoul, Korea) and incubated at $37^{\circ} \mathrm{C}$ for $24 \mathrm{~h}$ before counting the $S$. mutans colonies. The colony number of $S$. mutans in BHI medium without the probiotic strain was used as a negative control while PBS $(50 \mu \mathrm{L})$ was used as blank control. The inhibition (\%) was calculated as follows:

$$
\text { Inhibition }(\%)=(A-B) \times 100 / B
$$

where A—colony number of the experimental group, $\mathrm{B}$-negative control.

\subsection{Effect of SCSs on the Growth of S. mutans}

The effect of SCSs on the growth of S. mutans was measured by the method of Wasfi et al. [16]. S. mutans was grown at $37^{\circ} \mathrm{C}$ in BHI broth and diluted to $10^{8}$ cells $/ \mathrm{mL}$ with a BHI broth medium. SCSs $(100 \mu \mathrm{L})$ from each probiotic strain were mixed with an equal volume of $S$. mutans suspension placed in a 96-well microplate. The plate was further incubated at $37^{\circ} \mathrm{C}$ for $24 \mathrm{~h}$ and absorbance was measured at $600 \mathrm{~nm}$ using a microplate reader (Biotek Instruments Inc., Winooski, VT, USA). Sterilized MRS broth instead of SCS was used as a control. 


\subsection{Effect of SCSs on S. mutans-Induced Biofilm Formation}

The culture of $S$. mutans was adjusted to $10^{8} \mathrm{CFU} / \mathrm{mL}$ in BHI containing $0.2 \%$ sucrose, and aliquots of the culture $(100 \mu \mathrm{L})$ in the plate (96 well polystyrene plate; SPL Life Sciences Inc., Pocheon, Korea) were incubated overnight at $37^{\circ} \mathrm{C}$. The culture supernatant was replaced with the same volume of SCSs and incubated for another $48 \mathrm{~h}$ at $37^{\circ} \mathrm{C}$. After incubation, the medium was discarded, and the wells were thoroughly washed with sterilized distilled water. Then, the wells were stained with crystal violet solution $(0.5 \%$, $0.1 \mathrm{~mL}$ ) for $10 \mathrm{~min}$ and washed. After drying, the absorbance of solubilized blue-colored biofilm in the wells was measured at $595 \mathrm{~nm}$ using the microplate reader [20].

\subsection{RANKL-Induced Osteoclast Differentiation of Murine Osteoclast Progenitor RAW 264.7 Cells}

The RAW 264.7 macrophages were purchased from American Type Culture Collection (ATCC, Manassas, VA, USA) and cultured and maintained as previously described [22]. RAW 264.7 cells were seeded $\left(1 \times 10^{4}\right.$ cells /well $)$ and incubated at $37^{\circ} \mathrm{C}$ for $24 \mathrm{~h}$. $\alpha$-MEM (Welgene Inc., Daegu, Korea) containing RANKL (50 ng/mL; Prospec, Rehovot, Israel) and M-CSF ( $25 \mathrm{ng} / \mathrm{mL}$, Sigma-Aldrich, St. Louis, MO, USA) was used as a medium for differentiation from RAW 264.7 macrophages into osteoclasts. The medium was changed every other day during the incubation period. Cell viability was evaluated using MTT [3-(4,5-dimethylthiazol-2-yl)-2,5-diphenyltetrazolium bromide] assay.

\subsection{Tartrate-Resistant Acid Phosphatase-Positive (TRAP) Activity}

RAW 264.7 cells were seeded $\left(1 \times 10^{4}\right.$ cells/well $)$ and incubated for another 8 days in the presence of the samples. After cells were lysed using a Triton X-100/saline solution, they were dispersed in citrate buffer containing $10 \mathrm{mM}$ sodium tartrate and $10 \mathrm{mM} \mathrm{p}$ nitrophenylphosphate ( $\mathrm{pH} 4.7,50 \mathrm{mM})$. TRAP activity was measured at $405 \mathrm{~nm}$ after incubation for $30 \mathrm{~min}$ at $37^{\circ} \mathrm{C}$.

\subsection{RNA Extraction and Quantitative Real Time PCR ( $q R T-P C R)$}

RAW 264.7 cells were differentiated into osteoclasts for $42 \mathrm{~h}$ at various MG4265 SCS concentrations $(50 \mu \mathrm{g} / \mathrm{mL}, 100 \mu \mathrm{g} / \mathrm{mL}$, and $200 \mu \mathrm{g} / \mathrm{mL})$. The differentiated cells were isolated using NucleoZOL (QIAGEN, Hilden, Germany) and RNA was extracted according to the manufacturer's instruction. cDNA was synthesized using a cDNA kit (Applied Biosystems, Foster City, CA, USA), and quantitative relative expression of osteoclastspecific transcriptional factor genes (c-fos and NFATc1) and osteoclastogenesis-associated genes (TRAP, cathepsin K, and MMP-9) in RANKL-stimulated RAW 264.7 cells were analyzed by StepOne Plus RT-PCR system (Applied Biosystems, Foster City, CA, USA) using TaqMan ${ }^{\circledR}$ Master mix (Applied Biosystems) [22]. The housekeeping gene $\beta$-actin was used as a reference gene to normalize the target-gene expressions.

\subsection{Western Blotting Analysis}

RAW 264.7 cells were seeded in a 6-well plate at $1 \times 10^{5}$ cells/well and induced differentiation of osteoclast as described above. The cells were washed with cold PBS and lysed with a RIPA lysis buffer (ATTO, Tokyo, Japan) supplemented with phosphatase and protease inhibitors in a 98:1:1 $(\mathrm{v} / \mathrm{v} / \mathrm{v})$ ratio. Nuclear proteins were isolated using NE-PER ${ }^{\mathrm{TM}}$ nuclear and cytoplasmic extraction reagents (Thermo Scientific, Rockford, IL, USA) according to the manufacturer's instructions. Equal amounts of proteins, adjusted by the Bradford assay, were separated by SDS-PAGE (10\% acrylamide) and then transferred onto polyvinylidene fluoride membranes (Millipore, Billerica, MA, USA). The immunoreactive proteins of interest were visualized and quantified by an enhanced chemiluminescence detection system (Bio-Rad, Hercules, CA, USA) following incubation with primary antibodies (c-Jun N-terminal kinase (JNK), extracellular signal-regulated kinase (ERK), p38, nuclear factor $\mathrm{kB}(\mathrm{NF}-\mathrm{kB})$, heme oxygenase-1 (HO-1), $\beta$-actin, and TATA-binding protein (TBP); (Cell signaling Technology, Danvers, MA, USA)), followed by horse radish peroxidase conjugated secondary antibody (1:2500), as described previously [67]. The expressions of 
JNK, ERK, p38, and HO-1 were normalized to $\beta$-actin, whereas the expression of NF- $\mathrm{B}$ in the nucleus was normalized to TBP.

\subsection{Statistical Analysis}

All quantitative experiments were conducted in triplicate. Data were expressed as the mean \pm standard deviation and analyzed using SPSS 13.0 (SPSS, Inc., Chicago, IL, USA). One-way analysis of variance (ANOVA) and Duncan's multiple comparison tests were used to determine significant differences $(p<0.05)$ among treatment means.

\section{Conclusions}

SCS of L. salivarius MG4265 strongly inhibited S. mutans-induced biofilm formation and RANKL-induced osteoclastogenesis. The suppression of RANKL-induced activation of the MAPKs and NF- $\mathrm{kB}$ pathways and upregulation of $\mathrm{HO}-1$ expression inhibited the expression of transcriptional factors (c-fos and NFATc1) and osteoclastogenesis-related gene expression (TRAP, cathepsin K, and MMP-9). Therefore, SCS of L. salivarius MG4265 has great potential as a multifunctional oral health ingredient that inhibits not only biofilm formation but also suppresses the alveolar bone loss associated with periodontitis.

Author Contributions: Conceptualization, C.-H.K. and J.-Y.I.; methodology, T.H.N. and S.K.; validation, C.-H.K. and J.-Y.I.; formal analysis, J.-I.J., S.-M.B. and J.W.K.; investigation, J.-I.J., S.-M.B., T.H.N. and J.W.K.; data curation, S.K.; writing-original draft preparation, J.-I.J., S.-M.B., T.H.N.; writingreview and editing, C.-H.K. and J.-Y.I.; project administration, C.-H.K. and J.-Y.I.; funding acquisition, C.-H.K. and J.-Y.I. All authors have read and agreed to the published version of the manuscript.

Funding: This research was funded by the Ministry of Small and Medium Sized Enterprises (SMEs) and Startups (MSS), Korea, under the "Regional Star-Enterprise Development Program (R\&D, S2908142).

Data Availability Statement: Not applicable.

Acknowledgments: This research was financially supported by the Ministry of Small and Medium Sized Enterprises (SMEs) and Startups (MSS), Korea, under the "Regional Star-Enterprise Development Program (R\&D, S2908142)" supervised by the Korea Institute for Advancement of Technology (KIAT).

Conflicts of Interest: Nguyen, T.H.; Kim, J.W.; Kang, C.-H.; Kim, S are employee of MEDIOGEN. The funders had no role in the design of the study; in the collection, analyses, or interpretation of data; in the writing of the manuscript, or in the decision to publish the results.

Sample Availability: Samples of the compounds are available from the authors.

\section{References}

1. FAO/WHO. Evaluation of Health and Nutritional Properties of Probiotics in Food Including Powder Milk with Live Acid Bacteria. Report of a Joint FAO/WHO Expert Consultation, Córdoba, Argentina. 2001. Available online: https://www.who.int/ foodsafety/publications/fs_management/en/probiotics.pdf?ua=1 (accessed on 17 December 2020).

2. Yu, H.-S.; Lee, N.-K.; Choi, A.-J.; Choe, J.-S.; Bae, C.H.; Paik, H.-D. Antagonistic and antioxidant effect of probiotic Weissella cibaria JW15. Food Sci. Biotechnol. 2019, 28, 851-855. [CrossRef] [PubMed]

3. Wang, J.; Ji, H.; Wang, S.; Liu, H.; Zhang, W.; Zhang, D.; Wang, Y. Probiotic Lactobacillus plantarum promotes intestinal barrier function by strengthening the epithelium and modulating gut microbiota. Front. Microbiol. 2018, 9, 1953. [CrossRef] [PubMed]

4. Kim, H.-Y.; Bae, W.-Y.; Yu, H.-S.; Chang, K.-H.; Hong, Y.-H.; Lee, N.-K.; Paik, H.-D. Inula Britannica fermented with probiotic Weissella cibaria D30 exhibited anti-inflammatory effect and increased viability in RAW 264.7 cells. Food Sci. Biotechnol. 2020, 29, 569-578. [CrossRef] [PubMed]

5. Sánchez, B.; Delgado, S.; Blanco-Míguez, A.; Lourenço, A.; Gueimonde, M.; Margolles, A. Probiotics, gut microbiota, and their influence on host health and disease. Mol. Nutr. Food Res. 2017, 61, 1600240. [CrossRef]

6. Wegh, C.A.M.; Geerlings, S.Y.; Knol, J.; Roeselers, G.; Belzer, C. Postbiotics and their potential applications in early life nutrition and beyond. Int. J. Mol. Sci. 2019, 20, 4673. [CrossRef]

7. Aguilar-Toalá, J.; Garcia-Varela, R.; Garcia, H.; Mata-Haro, V.; González-Córdova, A.; Vallejo-Cordoba, B.; Hernández-Mendoza, A. Postbiotics: An evolving term within the functional foods field. Trends Food Sci. Technol. 2018, 75, 105-114. [CrossRef]

8. Moradi, M.; Kousheh, S.A.; Almasi, H.; Alizadeh, A.; Guimaraes, G.T.; Yilmaz, N.; Lotfi, A. Postbiotics produced by lactic acid bacteria: The next frontier in food safety. Compr. Rev. Food Sci. Food Saf. 2020, 19, 3390-3415. [CrossRef] 
9. Beristain-Bauza, S.C.; Mani-Lopez, E.; Palou, E.; Lopez-Malo, A. Antimicrobial activity of whey protein films supplemented with Lactobacillus sakei cell-free supernatant on fresh beef. Food Microbiol. 2017, 62, 207-211. [CrossRef]

10. Moradi, M.; Mardani, K.; Tajik, H. Characterization and application of postbiotics of Lactobacillus spp. on Listeria monocytogenes in vitro and in food models. LWT-Food Sci. Technol. 2019, 111, 457-464. [CrossRef]

11. Naito, M.; Yuasa, H.; Nomura, Y.; Nakayama, T.; Hamajima, N.; Hanada, N. Oral health status and health-related quality of life: A systematic review. J. Oral Sci. 2006, 48, 1-7. [CrossRef]

12. Dewhirst, F.E.; Chen, T.; Izard, J.; Paster, B.J.; Tanner, A.C.R.; Yu, W.-H.; Lakshmanan, A.; Wade, W.G. The human oral microbiome. J. Bacteriol. 2010, 192, 5002-5017. [CrossRef] [PubMed]

13. Saha, S.; Tomaro-Duchesneau, C.; Tabrizian, M.; Prakash, S. Probiotics as oral health biotherapeutics. Expert Opin. Biol. Ther. 2012, 12, 1207-1220. [CrossRef] [PubMed]

14. Forssten, S.D.; Bjorklund, M.; Ouwehand, A.C. Streptococcus mutans, acries and simulation models. Nutrients 2010, 2, 290-298. [CrossRef] [PubMed]

15. Schwendicke, F.; Korte, F.; Dorfer, C.E.; Kneist, S.; Fawzy El-Sayed, K.; Paris, S. Inhibition of Streptococcus mutans growthand biofilm formation by probiotics in vitro. Caries Res. 2017, 51, 87-95. [CrossRef] [PubMed]

16. Wasfi, R.; El-Rahman, O.A.A.; Zafer, M.M.; Ashour, H.M. Probiotic Lactobacillus sp. inhibit growth, biofilm formation and gene expression of caries-inducing Streptococcus mutans. J. Cell. Mol. Med. 2018, 22, 1972-1983. [CrossRef] [PubMed]

17. Lin, X.; Chen, X.; Chen, Y.; Chen, J.H. The effect of five probiotic lactobacilli strains on the growth and biofilm formation of Streptococcus mutans. Oral Dis. 2015, 21, e128-e134. [CrossRef]

18. Corrêa, M.G.; Pires, P.R.; Ribeiro, F.V.; Pimentel, S.Z.; Casarin, R.C.; Cirano, F.R.; Casati, M.Z. Systemic treatment with resveratrol and/or curcumin reduces the progression of experimental periodontitis in rats. J. Periodontal Res. 2017, 52, 201-209. [CrossRef]

19. Tóthová, L.U.; Celec, P. Oxidative stress and antioxidants in the diagnosis and therapy of periodontitis. Front. Physiol. 2017, 8, 1055-1068. [CrossRef]

20. Djordjevic, D.; Wiedmann, M.; Mclandsborough, L. Microtiter plate assay for assessment of Listeria monocytogenes biofilm formation. Appl. Environ. Microbiol. 2002, 68, 2950-2958. [CrossRef]

21. Liu, T.-H.; Tsai, T.-Y.; Pan, T.-M. Effect of ethanol extract from Lactobacillus paracasei subsp. Paracasei NTU 101 fermented skim milk on lipopolysaccharide-induced periodontal inflammation in rats. Food Funct. 2018, 9, 4916-4925. [CrossRef]

22. Kim, S.; Kang, S.-S.; Choi, S.-I.; Kim, G.-H.; Imm, J.-Y. Ecklonia cava extract containing dieckol suppresses RANKL-induced osteoclastogenesis via MAPkinase/NF-kB pathway inhibition and heme oxygenase-1 induction. J. Microbiol. Biothechnol. 2019, 29, 11-20. [CrossRef] [PubMed]

23. Simark-Mattson, C.; Emilson, C.G.; Håkansson, E.G.; Jacobsson, C.; Roos, K.; Holm, S. Lactobacillus-mediated interference of mutans streptococci in caries-free vs. caries-active subjects. Eur. J. Oral Sci. 2007, 115, 308-314. [CrossRef] [PubMed]

24. Tong, Z.; Zhou, L.; Li, J.; Kuang, R.; Lin, Y.; Ni, L. An in vitro investigation of Lactococus lactis antagonizing carriogenic bacterium Streptococcus mutans. Arch. Oral Biol. 2012, 57, 376-382. [CrossRef] [PubMed]

25. Kim, Y.J.; Lee, S.H. Inhibitory effect of Lactococcus lactis HY 449 on cariogenic biofilm. J. Microbiol. Biotechnol. 2016, 26, 1829-1835. [CrossRef] [PubMed]

26. Wu, C.-C.; Lin, C.-T.; Wu, C.-Y.; Peng, W.-S.; Lee, M.-J.; Tsai, Y.C. Inhibitory effect of Lactobacillus salivarius on Streptococus mutans biofilm formation. Mol. Oral Microbiol. 2015, 30, 16-26. [CrossRef]

27. Hasslöf, P.; Hedberg, M.; Twetman, S.; Stecksén-Blicks, C. Growth inhibition of oral mutans streptococci and candida by commercial probiotic lactobacilli-An in vitro study. BMC Oral Health 2010, 10, 18. [CrossRef]

28. Lin, X.; Chen, X.; Tu, Y.; Wang, S.; Chen, H. Effect of probiotic Lactobacilli on the growth of Streptococcus mutans and multispecies biofilms isolated from children with active caries. Med Sci. Monit. 2017, 23, 4175-4181. [CrossRef]

29. Saha, S.; Tomaro-Duchesneau, C.; Rodes, L.; Malhotra, M.; Tabrizian, M.; Prakash, S. Investigation of probiotic bacteria as dental caries and periodontal disease biotherapeutics. Benef. Microb. 2014, 5, 447-460. [CrossRef]

30. Caufield, P.W.; Schon, C.N.; Saraithong, P.; Li, Y.; Argimon, S. Oral Lactobacilli and dental caries: A model for niche adaptation in humans. J. Dent. Res. 2015, 94, 110S-118S. [CrossRef]

31. Marsh, P.D.; Head, D.A.; Devine, D.A. Dental plaque as a biofilm and a microbial community-Implications for treatment. J. Oral Biosci. 2015, 57, 185-191. [CrossRef]

32. Ansari, J.M.; Abraham, N.M.; Massaro, J.; Murphy, K.; Smith-Carpenter, J.; Fikrig, E. Anti-biofilm activity of a self-aggregating peptide against Streptococcus mutans. Front. Microbiol. 2017, 8, 488. [CrossRef] [PubMed]

33. Endo, K.; Mine, Y.; Shuto, T.; Taji, T.; Murayama, T.; Nikawa, H. Comprehensive analysis of transcriptional profiles in oral epithelial-like cells stimulated with oral probiotic Lactobacillus spp. Arch. Oral Biol. 2020, 118, 104832. [CrossRef] [PubMed]

34. Tahmourespour, A.; Kasra-Kermanshahi, R.; Salehi, R. Lactobacillus rhamnosus biosurfactant inhibits biofilm formation and gene expression of caries-inducing Streptococcus mutans. Dent. Res. J. 2019, 18, 87-94. [CrossRef]

35. Brzozowski, B.; Bednarski, W.; Gołek, P. The adhesive capability of two Lactobacillus strains and physicochemical properties of their synthesized biosurfactants. Food Technol. Biotechnol. 2011, 49, 177-186.

36. Ahn, K.B.; Baik, J.E.; Park, O.J.; Yun, C.H.; Han, S.H. Lactobacillus plantarum lipoteichoic acid inhibits biofilm formation of Streptococcus mutans. PLoS ONE 2018, 13, e0192694. [CrossRef]

37. Roodman, G. Advances in bone biology: The osteoclast. Endocr. Rev. 1996, 17, 308-332. 
38. Collin-Osdoby, P.; Osdoby, P. RANKL-mediated osteoclast formation from murine RAW 264.7 cells. Methods Mol. Biol. 2012, $816,187-202$.

39. Grigoriadis, A.E.; Wang, Z.Q.; Cecchini, M.G.; Hofstetter, W.; Felix, R.; Fleisch, H.A.; Wagner, E.F. c-Fos: A key regulator of osteoclast-macrophage lineage determination and bone remodeling. Science 1994, 266, 443-448. [CrossRef]

40. Zhao, Q.; Wang, X.; Liu, Y.; He, A.; Jia, R. NFATc1: Functions in osteoclasts. Int. J. Biochem. Cell. Biol. 2010, 42, 576-579. [CrossRef]

41. Fujisaki, K.; Tanabe, N.; Suzuki, N.; Kawato, T.; Takeichi, O.; Tsuzukibashi, O.; Makimura, M.; Ito, K.; Maeno, M. Receptor activator of NF-kappaB ligand induces the expression of carbonic anhydrase II, cathepsin K, and matrix metalloproteinase-9 in osteoclast precursor RAW264.7 cells. Life Sci. 2007, 80, 1311-1318. [CrossRef]

42. Huang, H.; Chang, E.-J.; Ryu, J.; Lee, Z.H.; Lee, Y.; Kim, H.-H. Induction of c-Fos and NFATc1 during RANKL-stimulated osteoclast differentiation is mediated by the p38 signaling pathway. Biochem. Biophys. Res. Commun. 2006, 351, 99-105. [CrossRef] [PubMed]

43. Matsuo, K.; Galson, D.L.; Zhao, C.; Peng, L.; Laplace, C.; Wang, K.Z.; Bachler, M.A.; Amano, H.; Aburatani, H.; Ishikawa, H.; et al. Nuclear factor of activated T-cells (NFAT) rescues osteoclastogenesis in precursors lacking c-Fos. J. Biol. Chem. 2004, 279, 26475-26480. [CrossRef] [PubMed]

44. Henriksen, K.; Tanko, L.B.; Qvist, P.; Delmas, P.D.; Christiansen, C.; Karsdal, M.A. Assessment of osteoclast number and function: Application in the development of new and improved treatment modalities for bone diseases. Osteoporos. Int. 2007, 18, 681-685. [CrossRef] [PubMed]

45. Hayman, A.R. Tartrate-resistant acid phosphatase (TRAP) and the osteoclast/immune cell dichotomy. Autoimmunity 2008, 41, 218-223. [CrossRef] [PubMed]

46. Wittrant, Y.; Theoleyre, S.; Couillaud, S.; Dunstan, C.; Heymann, D.; Redini, F. Regulation of osteoclast protease expression by RANKL. Biochem. Biophys. Res. Commun. 2003, 310, 774-778. [CrossRef] [PubMed]

47. Kim, J.-H.; Kim, E.-Y.; Lee, B.; Min, J.-H.; Song, D.-U.; Lim, J.-M.; Eom, J.W.; Yeom, M.; Jung, H.-S.; Sohn, Y. The effects of Lycii Radicis Cortex on RANKL-induced osteoclast differentiation and activation in RAW 264.7 cells. Int. J. Mol. Med. 2016, 37, 649-658. [CrossRef]

48. Lee, K.; Seo, I.; Choi, M.H.; Jeong, D. Roles of mitogen-activated protein kinases in osteoclast biology. Int. J. Mol. Sci. 2018, 19, 3004. [CrossRef]

49. Jimi, E.; Aoki, K.; Saito, H.; D’Acquisto, F.; May, M.J.; Nakamura, I.; Sudo, T.; Kojima, T.; Okamoto, F.; Fukushima, H.; et al. Selective inhibition of NF-kB blocks osteoclastogenesis and prevents inflammatory bone destruction in vivo. Nat. Med. 2004, 10, 617-624. [CrossRef]

50. Chung, Y.H.; Choi, B.; Song, D.H.; Song, Y.; Kang, S.W.; Yoon, S.Y.; Kim, S.W.; Lee, H.K.; Chang, E.J. Interleukin-1beta promotes the lc3-mediated secretory function of osteoclast precursors by stimulating the $\mathrm{Ca}^{2+}$-dependent activation of erk. Int. J. Biochem. Cell Biol. 2014, 54, 198-207. [CrossRef]

51. Han, Z.; Boyle, D.L.; Chang, L.; Bennett, B.; Karin, M.; Yang, L.; Manning, A.M.; Firestein, G.S. c-Jun N-terminal kinase is required for metalloproteinase expression and joint destruction in inflammatory arthritis. J. Clin. Invest. 2001, 108, 73-81. [CrossRef]

52. Matsumoto, M.; Kogawa, M.; Wada, S.; Takayanagi, H.; Tsujimoto, M.; Katayama, S.; Hisatake, K.; Nogi, Y. Essential role of p38 mitogen-activated protein kinase in cathepsin k gene expression during osteoclastogenesis through association of nfatc1 and pu.1. J. Biol. Chem. 2004, 279, 45969-45979. [CrossRef] [PubMed]

53. Lee, Z.H.; Kim, H.-H. Signal transduction by receptor activator of nuclear factor kappa B in osteoclasts. Biochem. Biophys. Res. Commun. 2003, 305, 211-214. [CrossRef]

54. Quach, D.; Parameswaran, N.; McCabe, L.; Britton, R.A. Characterizing how probiotic Lactobacillus reuteri 6475 and lactobacillic acid mediate suppression of osteoclast differentiation. Bone Rep. 2019, 11, 100227. [CrossRef] [PubMed]

55. Britton, R.A.; Irwin, R.; Quach, D.; Schaefer, L.; Zhang, J.; Lee, T.; Parameswaran, N.; Mccabe, L.R. Probiotic L. reuteri treatment prevents bone loss in a menopausal ovariectomized mouse model. J. Cell. Physiol. 2014, 229, 1822-1830. [CrossRef] [PubMed]

56. Lu, S.-H.; Chen, T.-H.; Chou, T.-C. Magnolol inhibits RANKL-induced osteoclast differentiation of RAW 264.7 cells through heme oxygenase-1-dependent inhibition of NFATC1 expression. J. Nat. Prod. 2015, 78, 61-68. [CrossRef]

57. Vijayan, V.; Wagener, F.A.D.T.G.; Immenschuh, S. The macrophage heme-heme oxygenase-1 system and its role in inflammation. Biochem. Pharmacol. 2018, 153, 159-167. [CrossRef]

58. Waddington, R.J.; Moseley, R.; Embery, G. Reactive oxygen species: A potential role in the pathogenesis of periodontal diseases. Oral Dis. 2000, 6, 138-151. [CrossRef]

59. Kwon, H.-J.; Kim, J.M.; Han, K.-I.; Jung, E.-G.; Kim, Y.H.; Patnaik, B.B.; Yoon, M.S.; Chung, S.K.; Kim, W.J.; Han, M.-D. Mutan: A mixed linkage $\alpha-[(1,3)$ - and $(1,6)]$-D-glucan from Streptococcus mutans, that induces osteoclast differentiation and promotes alveolar bone loss. Carb. Polym. 2016, 137, 561-569. [CrossRef]

60. Shimauchi, H.; Mayanagi, G.; Nakaya, S.; Minamibuchi, M.; Ito, Y.; Yamaki, K.; Hirata, H. Improvement of periodontal condition by probiotics with Lactobacillus salivarius WB21: A randomized, double-blind, placebo-controlled study. J. Clin. Periodontol. 2008, 35, 897-905. [CrossRef]

61. Ginsburg, I. Role of lipoteichoic acid in infection and inflammation. Lancet Infect. Dis. 2002, 2, 171-179. [CrossRef]

62. Teame, T.; Wang, A.; Xie, M.; Zhang, Z.; Yang, Y.; Ding, Q.; Gao, C.; Olsen, R.E.; Ran, C.; Zhou, Z. Paraprobiotics and postbiotics of probiotic Lactobacilli, their positive effects on the host and action mechanisms: A review. Front. Nutr. 2020, 7, 570344. [CrossRef] [PubMed] 
63. Lebeer, S.; Bron, P.A.; Marco, M.L.; Van Pijkeren, J.P.; Motherway, M.O.C.; Hill, C.; Pot, B.; Roos, S.; Klaenhammer, T. Identification of probiotic effector molecules: Present state and future perspectives. Curr. Opin. Biotechnol. 2018, 49, $217-223$. [CrossRef] [PubMed]

64. Zaiss, M.M.; Jones, R.M.; Schett, G.; Pacifici, R. The gut-bone axis: How bacterial metabolites bridge the distance. J. Clin. Invest. 2019, 129, 3018-3028. [CrossRef] [PubMed]

65. Liu, T.-H.; Tsai, T.-Y.; Pan, T.-M. Isolation and identification of anti-periodontitis ingredients in Lactobacillus paracasei subsp. paracasei NTU 101-fermented skim milk in vitro. J. Funct. Food 2019, 60, 103449. [CrossRef]

66. Krzyściak, W.; Kościelniak, D.; Papież, M.; Vyhouskaya, P.; Zagórska-Świeży, K.; Kołodziej, I.; Bystrowska, B.; Jurczak, A. Effect of a Lactobacillus salivarius probiotic on a double-species Streptococcus mutans and Candida albicans caries biofilm. Nutrients 2017, 9, 1242. [CrossRef]

67. Lee, D.; Imm, J.-Y. AMP kinase activation and inhibition of nuclear factor-kappa B (NF-kB) translocation contribute to the anti-inflammatory effect of tricin. J. Food Biochem. 2017, 41, e12293. [CrossRef] 